\title{
A Crossover Study of English Proficiency Test For Communication in Nurse Anaesthetist Students
}

\author{
Hortrakul, P., Yangan, K., Phoson, P., Charoensri, A., Vichitvejpaisal, P. \& Sombood, P.
}

\begin{abstract}
Introduction: English is a second language for Thai students. Consequently, it becomes a crucial issue for medical school authorities to command an efficient academic curriculum, particularly which of a nurse anaesthetist training program.
\end{abstract}

Objective: To assess English communication proficiency among nurse anaesthetist students by means of online video and in-class teaching courses.

Methods: This was a crossover study design. Thirty-six students were stratified and randomized into two groups. There were two learning courses (online video and in-class teaching) with the same didactic information. All participants had to attend two sessions to accomplish the process. Each session was two weeks apart where they performed a well-validated, multiple-choice question as pre-test and posttest prior to and immediately after the learning course. The tools having the same neurobehavioral assessment were re-allocated to prevent carry-over effect. The achievement and relative growth scores were determined to assess learning outcomes.

Results: The baseline scores were similar, while the post-test and the relative growth scores between the two groups appeared to increase insignificantly throughout the study. However, the online video course participants showed superior learning achievement scores than those of in-class teaching.

Conclusion: Nurse Anaesthetist students attending the online video course showed better learning achievement scores than those attending in-class teaching.

Keywords: English communication, Online video teaching; In-class teaching

\section{Introduction}

The nurse anaesthetist training program has been established since 1969. This project is under the supervision of the Royal College of Anaesthesiologists of Thailand with the main purpose of solving a shortage of doctors in provincial areas.

The one-year program consists of theoretical practice in basic sciences and clinical anaesthesia as well as professional lawsuits. Nurses should have competency in anaesthetic management including premedication, induction, maintenance, reversal and handling

Department of Anesthesiology, Faculty of Medicine Siriraj Hospital, Mahidol University, Bangkok 10700, Thailand.

Corresponding Author: Phongthara Vichitvejpaisal Department of Anesthesiology, Faculty of Medicine Siriraj Hospital, Mahidol University, Bangkok 10700, Thailand.

Email: phongthara@gmail.com of adverse events during the procedural process. They not only work laboriously day and night in the operating theatre, but also take preoperative and post-operative visits to their patients at wards. Furthermore, they are ready to cope with critically unexpected situations (Wren, 2001).

Since Thailand, a developed country, has recently joined the Asean Economic Community (AEC), she needs qualified whitecollar workers to deal with advances in information and technology. This would help Thailand to upgrade her facilities and health processes to become an international medical hub of the region (Kourkouta \& Papathanasiou, 2014).

As a university and a tertiary hospital, Siriraj is ready to improve herself not only in innovative technology, academic programs, and research studies but also in professional personnel. This is because the divergence of medical 
knowledge must be competitive, given an increasing number of patients and diseases (Luiz et al., 2015). As a result, nurses have become skilled manpower and resources in response to line management requests (Mullan \& Kothe, 2010). They work at the forefront to communicate and serve patients in every step of medical treatment and nursing care (Wren, 2001; Kourkouta \& Papathanasiou, 2014; Cross \& Smalldridge, 2011; Georgiadou, 2013).

English is a second language for Thai students and is spoken among scholars in very few big cities. Still, nurses have problems in English practice since most of them are trained in remote, domestic universities (Wren, 2001; Mullan \& Kothe, 2010; Wikström \& Svidén, 2011; Liu \& Littlewood, 1997). Consequently, it becomes a crucial issue for medical school authorities to command an efficient academic curriculum, particularly which of a nurse anaesthetist training program.

Nowadays, the online learning method helps to encourage greater knowledge acquisition since it is challenging and stimulating to students (Heath et al., 2008; Shield et al., 2011; Sun et al., 2014; Tan et al., 2015). In addition, the viability of a wireless network relies on the recently available internet (Mash et al., 2006). As a result, investigators would like to compare two learning methods-online video and inclass teaching-in promoting students' learning achievement in English communication proficiency.

\section{Methods}

This prospective, crossover study has been approved by Siriraj Institutional Review Board (COA: Si622/2018) and registered via Thai Clinical Trial Registry (TCTR20191029001). The data were collected in the 2018-2019 academic year. The inclusion criterion was 40 nurse anaesthetist students in the learning program. They all volunteered to join the study without any honorarium. The exclusion criterion was any students who felt awkward, uneasy joining the study and could withdraw any time. The participants were informed about the study's significance under the department policy as well as the learning objectives in details. After signing the consent forms, they were equally stratified and randomized into group $A$ and group $B$, and then performed the pre-test exam.

There were two learning courses: In-class teaching (IC) and Online video (OV). The IC was conventionally set up in a room by the same instructor with experience in teaching and speaking English for more than 20 years. The OV, however, was an open access, online application (http://voa.com). Students were assigned to log-in and explore the website at the computer training centre. Simultaneously, both one-hour learning courses had the same didactic information.

Students in group A first joined the IC while the others attended the OV. After two weeks, they performed a crossover study. The pre-test (X) and post-test $(Y)$ scores were noted for analysis.

A 40-item, paper-pencil, multiple-choice question test was developed for the table of specifications and knowledge map concerning peri-anaesthesia communication skills. The content validity and objectivity were determined by two board-certified anaesthesiologists, who had at least 10-year experience in educational evaluation. A try-out was performed for appropriateness by 10 novice nurse anaesthetists.

The pre-test and post-test exams were the tools with the same neurobehavioral assessment. However, the contents were re-allocated to prevent carry-over effect. This 30-minute test was arranged in class, prior to and immediately after the learning course.

In brief, there were two learning courses with the same didactic information via different media. All participants had to attend two sessions to accomplish the process. Each session was two weeks apart where they performed a well-validated, multiple-choice question as pre-test and post-test prior to and immediately after the learning course. The tools having the same neurobehavioral assessment were re-allocated to prevent carryover effect.

\section{Results}

Pretest (AX1, BX1, AX2, and BX2) and posttest (AY1, BY1, AY2, and BY2) scores were recorded. In addition, the relative growth of knowledge (G1, G2) was calculated as follows (Kanjanawasri, 1989; Apidechakul et al., 2017; Vichitvejpaisal et al., 2011):

$$
\begin{aligned}
& \mathrm{GA} 1=100(\mathrm{AY} 1-\mathrm{AX} 1) /(\mathrm{F}-\mathrm{AX} 1) \% \\
& \mathrm{GA2}=100(\mathrm{AY} 2-\mathrm{AX} 2) /(\mathrm{F}-\mathrm{AX} 2) \% \\
& \mathrm{~GB} 1=100(\mathrm{BY} 1-\mathrm{BX} 1) /(\mathrm{F}-\mathrm{BX} 1) \% \\
& \mathrm{~GB} 2=100(\mathrm{BY} 2-\mathrm{BX} 2) /(\mathrm{F}-\mathrm{BX} 2) \%
\end{aligned}
$$




\begin{tabular}{|c|c|c|c|}
\hline \multicolumn{2}{|c|}{ Group A } & \multicolumn{2}{|c|}{ Group B } \\
\hline$A X_{1}$ & $=$ Pre-test 1 & $\mathrm{BX}_{1}$ & $=$ Pre-test 1 \\
\hline $\mathrm{AY}_{1}$ & $=$ Post-test 1 & $\mathrm{BY}_{1}$ & $=$ Post-test 1 \\
\hline$A X_{2}$ & $=$ Pre-test 2 & $\mathrm{BX}_{2}$ & = Pre-test2 \\
\hline $\mathrm{AY}_{2}$ & = Post-test2 & $\mathrm{BY}_{2}$ & = Post-test2 \\
\hline $\mathrm{GA}_{1}$ & $=$ Growth score 1 & $\mathrm{~GB}_{1}$ & $=$ Growth score 1 \\
\hline $\mathrm{GA}_{2}$ & $=$ Growth score 2 & $\mathrm{~GB}_{2}$ & $=$ Growth score 2 \\
\hline \multicolumn{4}{|c|}{$F=$ Full scores of the learning courses } \\
\hline
\end{tabular}

\section{Statistical analysis}

By using the Statistical Package for Social Sciences for Windows 18.0, all categorical data were conveyed in percentage and frequency. The pre-test, post-test and relative growth scores between the two groups were expressed as the mean and standard deviation and then compared by the non-dependent $t$ test. $A p<$
0.05 was considered statistically significant difference with a $95 \%$ confidence interval.

\section{Results}

The index of item objective congruence was 0.82 , the internal consistency with Kuder Richardson 21 was 0.8 , and the criterionreferenced items of difficulty and discrimination index were 0.4-0.6 and 0.6-0.8 respectively.

\section{Table 1: Participants' characteristics}

\begin{tabular}{lccccc}
\hline & & Gr.1 & Gr.2 & Average & P-value \\
\hline \multirow{2}{*}{ Gender } & Female & $83 \%$ & $89 \%$ & $86.1 \%$ & 0.349 \\
& Male & $17 \%$ & $11 \%$ & $13.9 \%$ & \\
Age (years) & & 29.8 & 28.3 & 29.2 & 0.949 \\
Working Experience (years) & 4.4 & 5.1 & 4.8 & 0.649 \\
$1^{\text {st }}$ English pre-test scores & & $15.67 \pm 3.38$ & $16.78 \pm 2.71$ & $16.07 \pm 3.30$ & 0.367 \\
\hline
\end{tabular}

Four and six students dropped out between the first and second learning courses respectively due to emergency calls. The demographic characteristics of both groups including gender, age and working experience were comparable (Table 1).

The first and second pre-test, the first post-test and the first growth scores between the two groups were $15.7 \pm 3.4$ and $16.8 \pm 2.7,17.2 \pm 1.9$ and $17.3 \pm 1.4,17.9 \pm 2.9$ and $18.1 \pm 1.8$, as well as $21.2 \pm 9.2$ and $34.1 \pm 6.4$ respectively, showing no statistically significant differences (Table 2 ).

In addition, after two weeks the second posttest and the second growth scores between the two groups were $19.3 \pm 1.2$ and 19.1 \pm 1.4 ,
$35.7 \pm 6.3$ and $26.0 \pm 5.6$ correspondingly, showing insignificant differences.

Interestingly, the OV had higher first and second growth scores than those of the IC (34.9\% and $23.6 \%$ respectively).

\section{Discussion}

At the beginning, the baseline scores of both learning courses were similar. In addition, the post-test and the relative growth scores between the two groups appeared to increase insignificantly throughout the study. However, the online video course showed better learning achievement scores than those of in-class teaching. 


\begin{tabular}{|c|c|c|}
\hline Learning Course & In-class Teaching (IC) & Video Online (VO) \\
\hline & $A(n=18)$ & $B(n=18)$ \\
\hline \multirow[t]{2}{*}{ Student (Groups) } & $A X_{1}$ & $\mathrm{BX}_{1}$ \\
\hline & $A Y_{1}$ & $\mathrm{BY}_{1}$ \\
\hline \multicolumn{3}{|c|}{2 weeks } \\
\hline \multirow{3}{*}{ Student (Groups) } & $B(n=17)$ & $A(n=17)$ \\
\hline & $\mathrm{BX}_{2}$ & $\mathrm{AX}_{2}$ \\
\hline & $\mathrm{AY}_{2}$ & $\mathrm{BY}_{2}$ \\
\hline
\end{tabular}

\section{Figure 1: A crossover study design of nurse anaesthetist students on English proficiency test with the two learning courses: Online Video (OV) and In-class Teaching (IC)}

The comparable baseline scores implied that students had even knowledge. Therefore, the intervention applied as learning techniques could provide its unique effects on the students' accomplishment.

Clinically, students of the online video course achieved better scores. This was supported by many studies. Vichitvejpaisal et al., (2011) in a study on a comparison of knowledge retention between online and in-class problem-based learning, concluded that online teaching yielded superior knowledge retention. The key success factors might depend on students' achievement motives and a sense of self-actualization (Neto, 2015).

Table 2: Pre-test (AX1, BX1, AX2, and BX2), post-test (AY1, BY1, AY2, and BY2) and relative growth of knowledge (GA1, GB1, GA2 and GB2) during OV and IC learning courses

\begin{tabular}{|c|c|c|c|c|c|c|c|c|}
\hline & & $\mathrm{X} 1$ & Y1 & G1 & $\begin{array}{c}\text { After } \\
2 \text { weeks }\end{array}$ & $\mathrm{X} 2$ & Y2 & G2 \\
\hline Gr. A & IC & $\begin{array}{r}16.78 \\
\pm 2.71\end{array}$ & $\begin{array}{r}18.05 \\
\pm 1.76\end{array}$ & $\begin{array}{c}21.2 \\
\pm 9.19\end{array}$ & OV & $\begin{array}{r}17.18 \\
\pm 1.89\end{array}$ & $\begin{array}{r}19.29 \\
\pm 1.16\end{array}$ & $\begin{array}{c}35.7 \\
\pm 6.30\end{array}$ \\
\hline Gr. B & VO & $\begin{array}{r}15.67 \\
\pm 3.38\end{array}$ & $\begin{array}{r}17.94 \\
\pm 2.86\end{array}$ & $\begin{array}{c}34.1 \\
\pm 6.43\end{array}$ & IC & $\begin{array}{r}17.29 \\
\pm 1.40\end{array}$ & $\begin{array}{l}19.12 \\
\pm 1.40\end{array}$ & $\begin{array}{r}26.0 \\
\pm 5.64\end{array}$ \\
\hline $\mathrm{P}$-value & & 0.367 & 0.114 & 0.156 & & 0.136 & 0.846 & 0.578 \\
\hline
\end{tabular}

In addition, Ram et al., in a study on the effectiveness of computer-aided instruction courseware developed with interactive multimedia concepts for teaching phase III MD students, claimed that students taught with the CAl multi-media courseware performed significantly better than those taught with the conventional method (Ram et al., 2009). Modica et al., in a study on teaching musculoskeletal physical diagnosis using a web-based tutorial and pathophysiologyfocused cases, concluded that a web-based experimental curriculum was as effective as the traditional curriculum for teaching the musculoskeletal exam. Additionally, users were satisfied with web-based training and benefited from a persistent resource (Modica et al., 2009).

However, many studies pointed out that most students worldwide still prefer traditional classes because online courses lack accreditation and quality, face-to-face interaction, require more work, and call for intense self-discipline and self-direction.

As for discontented outcomes of the study, plausible explanations are as follows.

First, English is a second language. Most students lack a sense of self-directed learning (SDL) in schools; a few earn experience as late 
as in universities. Thus it is a tough assignment for nurses to familiarize themselves with English communication.

This was inconsistent with Du (2013) in a study on perspectives of SDL learning in a community college. He subscribed to the utility of SDL as a potent learning strategy for students of foreign languages because SDL could lead to improvements in the knowledge domain, metacognitive skills, and motivation (Du, 2013). In addition, Kuama and Intharaksa (2016) and Vincent and Kopp (2000) in a study of online learning for all English language students, mentioned that low-English-proficiency students lacked online learning skills and experiences in SDL, so they might not be ready for learning English online (Kuama \& Intharaksa, 2016; Vincent \& Kopp, 2000).

Second, anaesthesia personnel work at the forefront of medical practice. Though anaesthesia is charged with medical, ethical, and legal issues, they are usually busy with their tasks and hardly perform the pragmatic approach of verbal communication with patients peri-operatively.

Research on anaesthesiologists and perioperative communication implied that patient care is where professionalism receives its first expression. Importantly, cultural and language barriers influenced pre-anaesthetic history-taking and post-anaesthetic pain management. With little known about the patient, much about them must be inferred (Vincent \& Kopp, 2000).

In addition, Smith and Mishra (2010) in an article on interaction between anaesthetists, their patients, and the aesthesia team, mentioned that communication is a key skill for anaesthetic practice, in which the style of talking reflects an implied relationship between the sender and the recipient. Moreover, information on patients serves as an opportunity to review the continuing care the patient has received and to plan for further progress (Smith \& Mishra, 2010).

Third, nurse anaesthetist students work strenuously under the supervision of medical and nurse staff. Furthermore, the hours of study and night-shift work tighten their academic curriculum. As a result, they become too exhausted to cooperate in the project. In other words, fatigue plays a causal or contributory role in the interventional program.

Studies showed that anaesthesia providers were required to vigilantly care for patients any time of day or night. This often conflicted with their physiological demands. Fatigue and sleep deprivation affected impact performance and mood (Paterson et al., 2013). Additionally, work on chronic partial-sleep deprivation provided important information to practicing clinicians, particularly cognitive performance deficits, prolonged reaction time, and poor communication (Alhola \& Polo, 2007).

Finally, after graduation most students must repay their sponsoring hospitals. There, they work with people who speak colloquial native tongues. Their opportunities for English practice to build rapport with patients and their relatives usually shrink, soon approaching zero. Thus the continuation of English for nursing is crucial to enable them to work more confidently and effectively.

One article supported the development of the English learning process especially in nursing. Communicative language teaching set principles for the teaching of communicative competence that confined both verbal and written communication. The course focused on authentic tasks and activities based on everyday nursing and healthcare scenarios (Huang, 2016; Diana, 2014; Toro et al., 2018).

\section{Conclusion}

Nurse anaesthetist students attending the online video course showed better learning achievement scores than those of in-class teaching. The baseline scores were similar, while the post-test and the relative growth scores between the two groups appeared to increase insignificantly throughout the study.

\section{Conflict of Interest}

The author declares no conflict of interest.

\section{Suggestion for future study}

The on-line teaching represents a technological innovation that can change the learning process as seen in the presence and accessibility of a growing number of online courses and programs in higher education today.

\section{Acknowledgements}

The authors thank Mr. Konthi Kulachol for language editing and proofreading, and $\mathrm{Mr}$. Suthiphol Udompandurak, Clinical Epidemiology Unit, Faculty of Medicine Siriraj 
Hospital, Mahidol University, for statistical analysis.

\section{References}

Alhola, P. \& Polo-Kantola, P. (2007). Sleep Deprivation Impact on Cognitive Performance. Neuropsychiatric Disease and Treatment, 3, 5, pp. 553-568.

Apidechakul, P., Vichitvejpaisal, P., Jirativanont, T., Triyasunant, N., Iramaneerat, C. \& Udompandurak, S. (2017). Crossover Study in Simulation-Based and Problem-Based Learning in Difficult Airway Management. Medical Education Publish, 6, 1, pp. 1-10.

Cross, D. \& Smalldridge, A. (2011). Improving Written and Verbal Communication Skills for International Medical Graduates: A Linguistic and Medical Approach. Medical Teacher, 33, 7, pp. E364-367.

Diana, S. (2014). Communicative Language Teaching and Its Misconceptions about the Practice in English Language Teaching (Elt). Bahasa \& Sastra, 14, 1, pp. 36-44.

Du, F. (2013). Student Perspectives of Self-Directed Language Learning: Implications for Teaching and Research. International Journal for The Scholarship of Teaching and Learning, 7, 2, pp. 1-17.

Georgiadou, L. (2013). 'My Language Thing Is Like a Big Shadow Always Behind Me': International Counselling Trainees' Challenges in Beginning Clinical Practice. Counselling and Psychotherapy Research, 14, 1, pp. 10-18.

Heath, S., Higgs, J. \& Ambruso, D. R. (2008). Evidence of Knowledge Acquisition in a Cognitive Flexibility-Based Computer Learning Environment. Medical Education Online, 13, pp. 1-16.

Huang, S.H. (2016). Communicative Language Teaching: Practical Difficulties in the Rural Efl Classrooms in Taiwan. Journal of Education and Practice, 7, 24, pp. 186- 203.

Kanjanawasri, S. (1989). Alternative Strategies for Policy Analysis: An Assessment of School Effects on Students Cognitive and Affective Mathematics Outcomes in Lower Secondary School in Thailand. University of California. United State of America.

Kim, M. \& Park, S.Y. (2011). Factors Affecting the Self-Directed Learning of Students at Clinical Practice Course for Advanced Practice Nurse. Asian Nursing Research, 5, 1, pp. 48-59.

Kopp, V. J. \& Shafer, A. (2000). Anesthesiologists and Perioperative Communication. Anesthesiology, 93, pp. 548-555.
Kuama, S. \& Intharaksa, U. (2016). Is Online Learning Suitable for All English Language Students. Pasaa, 52, pp. 53-82.

Kourkouta, L. \& Papathanasiou, I. V. (2014). Communication in Nursing Practice. Mater Sociomed, 26, 1, pp. 65-67.

Liu, N.F. \& Littlewood, W. (1997). Why Do Many Students Appear Reluctant To Participate in Classroom Learning Discourse?. System, 25, 3, pp. 371-384.

Luiz Adrian, J. A., Zeszotarski, P. \& Ma, C. (2015). Developing Pharmacy Student Communication Skills through Role-Playing and Active Learning. American Journal of Pharmaceutical Education, 79, 3, pp. 44-52.

Mash, B., Marais, D., Van Der Walt, S., Van Deventer, I., Steyn, M. \& Labadarios, D. (2006). Assessment of the Quality of Interaction in Distance Learning Programmes Utilizing the Internet or Interactive Television: Perceptions of Students and Lecturers. Medical Teacher, 28, 1, pp. E1-9.

Modica, R. F., Thundiyil, J. G., Chou, C., Diab, M. \& Von, S. E. (2009). Teaching Musculoskeletal Physical Diagnosis Using a Web-Based Tutorial and Pathophysiology-Focused Cases. Medical Education Online, 14, pp. 1-13.

Mullan, B. \& Kothe, E. J. (2010). Evaluating a Nursing Communication Skills Training Course the Relationships Between Self-Rated Ability, Satisfaction, and Actual Performance. Nurse Education in Practice, 10, 6, pp. 374-380.

Neto, M. (2015). Educational Motivation Meets Maslow: Self-Actualisation as Contextual Driver. Journal of Student Engagement: Education Matters, 5, 1, pp. 18-29.

Paterson, J.L., Dorrian, J., Ferguson, S.A., Jay, S.M. \& Dawson, D. (2013). What happens to mood, performance and sleep in a laboratory study with no sleep deprivation? Sleep and Biological Rhythms, 11, 3, pp. 200-209.

Ram, S. P., Phua, K. K. \& Ang, B. S. (2009). The Effectiveness of a Computer-Aided Instruction Courseware Developed Using Interactive Multimedia Concepts for Teaching Phase III Md Students. Medical Teacher, 19, 1, pp. 51-52.

Shield, R. R., Tong, I., Tomas, M. \& Besdine, R. W. (2011). Teaching Communication and Compassionate Care Skills: An Innovative Curriculum for Pre-Clerkship Medical Students. Medical Teacher, 33, 8, pp. E408-416.

Smith, A. F. \& Mishra, K. (2010). Interaction between Anaesthetists, Their Patients, and the Anaesthesia Team. British Journal of Anaesthesia, 105, 1, pp. 60-68. 
Sun, X., Wu, Y. \& Ni, B. (2014). Interdisciplinary Strategy to Train Graduate Students in English Communication for International Academic Conferences. Medical Teacher, 36, 2, pp. 180182.

Tan, X., Chen, M., Chen, X., Liao, R. \& Sun, J. (2015). A Shift of Focus is required in English Courses for Chinese Medical Postgraduates. Medical Teacher, 37, 4, pp. 403-404.

Toro, V., Camacho-Minuche, G., Pinza-Tapia, E. \& Paredes, F. (2018). The Use of the Communicative Language Teaching Approach to Improve Students' Oral Skills. English Language Teaching, 12, 1, pp. 110-118.
Vichitvejpaisal, P., Panjamawat, T. \& Varasunun, P. (2011). A Comparison of Knowledge Retention between Online and In-Class Problem-Based Learning. South-East Asian Journal of Medical Education, 5, 2, pp. 41-47.

Warschauer, M. (2002). A Developmental Perspective on Technology in Language Education. Technology in Language Education, 36, 3, pp. 453-475.

Wikström, B.-M. \& Svidén, G. (2011). Exploring Communication Skills Training in Undergraduate Nurse Education by Means of a Curriculum. Nursing Reports, 1, 1, pp. 7-13.

Wren, K. R. (2001). Learning from a Nurse Anesthetist Perspective: A Qualitative Study. AANA Journal, 69, 4, pp. 273-278. 